\title{
POBLACIÓN Y ENCOMIENDAS EN EL NORDESTE ARGENTINO. EL CASO DE CORRIENTES EN EL SIGLO XVII Y PRINCIPIOS DEL XVIII SEGÚN LAS VISITAS DE INDIOS. ${ }^{1}$
}

\section{María Laura Salinas}

Las visitas realizadas a la ciudad de Corrientes (ubicada en el actual nordeste argentino) y a los pueblos de indios que pertenecieron a su jurisdicción durante los siglos XVII y XVIII, constituyen fuentes interesantes y en algunos aspectos "generosas" por la información específica que ofrecen sobre la población indígena encomendada que habitaba en las reducciones y en la ciudad como yanaconas sirviendo en las casas o chacras de los encomenderos. Siendo el objetivo conocer detalles de la población tributaria y sus familias e intervenir ante posibles irregularidades, los informes destacan especialmente el estado cuantitativo y algunos aspectos de la situación de los indígenas de los cuatro pueblos de indios de la región: Itatí, conformada por guaraníes y Santiago Sánchez, Candelaria de Ohoma, Santa Lucía de los Astos constituidas por grupos chaqueños.

Una de las principales preguntas que surgen permanentemente al realizar nuestra investigación, es hasta qué punto estas fuentes contribuyen a la reconstrucción de la realidad demográfica de estas poblaciones. Nos proponemos, entonces en este trabajo reflexionar acerca de las posibilidades y limitaciones que ofrecen los datos aportados por estos documentos oficiales, teniendo en cuenta que son casi los únicos disponibles de ésta época en la región.

\section{Las visitas de indios como fuentes}

Desde hace algún tiempo venimos trabajando con visitas de indios realizadas a la jurisdicción de Corrientes y Paraguay, espacio geográfico que abordamos específicamente en nuestras investigaciones. Nos inclinamos especialmente al estudio del siglo XVII, aunque para reflexionar en este trabajo decidimos incursionar también en el siglo XVIII concretamente para la región de Corrientes, por las fuentes con las que trabajamos.

Nuestro universo de estudio está relacionado con la encomienda y los actores que la conformaron, nos interesa especialmente analizar las características de este régimen en Corrientes y sus pueblos de indios en este período. Intentamos reconstruir algunos aspectos de las relaciones entre feudatarios y encomendados, el sistema de trabajo en el que estaban insertos los indígenas, el tributo, la legislación y ocupa un espacio muy importante en

\footnotetext{
${ }^{1}$ Este trabajo fue presentado en el Taller "Las Poblaciones Históricas" organizado por la Comisión de Demografía Histórica de la AEPA y el Instituto Ravignani, en Mayo de 2005.
} 
nuestro interés abordar el estudio de la población en estas encomiendas, su evolución y sus particularidades.

Hemos utilizado específicamente para el tema de la población visitas de indios realizadas a la región durante el siglo XVII desde la Audiencia de la ciudad de La Plata y durante el XVIII, visitas "locales" realizadas desde la gobernación. Con notables diferencias entre las que se realizaron en un siglo y otro, no dejan de constituirse en fuentes muy valiosas.

Desde la llegada de los europeos al continente americano, surgió la necesidad de realizar controles e inventarios tanto de los recursos materiales como humanos. La expansión permanente de sus territorios, acompañada del objetivo evangelizador, hizo que la corona necesitara de información abundante. Al interés económico que podía representar la población, se agregó una estrecha vigilancia sobre ella por motivos religiosos o culturales.

La región de Corrientes no escapó a este sistema de "vigilancia" y, aunque con inspecciones esporádicas, se aplicó la misma metodología que en el resto del imperio.

\section{Las visitas a la tierra: Historia e Historiografía}

Antes de ingresar en la problemática de la utilización de estas fuentes en Corrientes consideramos necesario hacer algunas referencias a la historia e historiografía de las visitas para poder comprender mejor las particularidades que se dieron en su aplicación.

Quizás el trabajo más completo y pionero referido al estudio de la visita como institución, que profundiza en sus detalles y características sea el estudio de Guillermo Céspedes del Castillo, realizado hace sesenta años. ${ }^{2}$ De un modo general y haciendo hincapié en lo cualitativo, divide Céspedes las visitas en generales y específicas, interesándose mucho más por las primeras que, por su importancia y por abarcar la amplitud de un virreinato, han sido más estudiadas. Entre las visitas específicas, incluye a las visitas que los oidores realizaban a los territorios de su audiencia. ${ }^{3}$

Las visitas a la tierra quedan bien descriptas por su mismo nombre, pues, efectivamente, el visitador había de recorrer los pueblos de indios, e incluso las tierras, para delimitar los linderos de las mismas. El título XXXI del libro 2 de la Recopilación ${ }^{4}$, sintetiza los fines de estas comisiones a oidores: informar de la doctrina y de las tasas de tributos (ley 8), procurar que tengan bienes de comunidad (ley 9), informar de su buen trato y castigo de los culpados (ley10), informar del trato que hacen los caciques a los indios (ley 11). De la libertad de los indios (ley 12) etc. En cada lugar, según las necesidades,

\footnotetext{
${ }^{2}$ Guillermo Céspedes del Castillo. "La visita como institución indiana". En: Anuario de Estudios Americanos, III, 1946, Pág. 984-1025

${ }^{3}$ Esta división, en realidad Céspedes la toma de Clarence Haring. Julián Ruiz Rivera en su artículo "Las visitas a la tierra en el siglo XVII como fuente de Historia Social" En: Estudios sobre política indigenista española en América. 3 vol., Valladolid 1975-1977. p. 2, no considera apropiada esta división porque generales son denominadas las visitas de un oidor al distrito de la audiencia, si este iba investido de las facultades normales. No sería general, sin embargo, la comisión de un oidor para visitar cierto distrito de trapiches, obrajes o minas.

${ }^{4}$ Recopilación de Leyes de los Reinos de Indias, Madrid, Consejo de la Hispanidad, 1943.
} 
éstos objetivos eran desglosados en cuestionarios de preguntas, por las que se guiaba el visitador en los interrogatorios.

Con respecto a la expresión "visita general" se aplica no sólo a las que se dispusieron desde España, sino también a la que los virreyes hicieron a todo el territorio de su jurisdicción, como la famosa del virrey del Perú, Francisco de Toledo, y, más impropiamente, a la que uno de ellos, el virrey de Nueva España, conde de Monterrey, hizo a las minas de Pachuca ${ }^{5}$ Los documentos coloniales combinan el término con varios adjetivos "visita general" era una inspección general, "visita eclesiástica" era una inspección religiosa, "visita universitaria" era una inspección a una institución académica. ${ }^{6}$

Como una investigación regional, la visita inevitablemente quería decir tener contacto con los indios coloniales. Este escrutinio de gente nativa hace su investigación de particular interés para los investigadores dedicados al desarrollo de las sociedades e instituciones nuevas en América. En su estudio del Juzgado General de Indios en Nueva España, Woodrow Borah define la visita en término de su esfera local y la evaluación de los niveles de impuestos. ${ }^{7}$

En América del Sur y los Andes centrales, la historiografía de la visita gira en torno a sus características rurales e indígenas, María Rostorowsky describe lo que llama "Visita de indios". Ofrece una tipología de tres niveles: número de población, divisiones de tierra e investigaciones de hogar a hogar para incluir las variantes de tipos y señala que con estos datos, las autoridades españolas determinaban el nivel de tributo y la sucesión de los puestos indígenas ${ }^{8}$ Hermes Tovar atribuye características similares a las visitas, en su estudio sobre la visita realizada en 1539 a la provincia de Mariquita en Colombia, Tovar caracteriza la institución como un instrumento de mediar entre los conquistadores y conquistados, con el fin de extraer información indígena para posponer las caídas de las poblaciones nativas. ${ }^{9}$

Una de las contribuciones de mayor relevancia, fue indudablemente el aporte de John Murra, quien elevó la visita a una posición crítica para comprender el mundo indígena andino. La publicación en equipo de las ediciones académicas de las visitas a Chucuito y Huanuco ${ }^{10}$, a mediados de los años 1960, dio ímpetu tanto a la investigación

\footnotetext{
${ }^{5}$ Estos ejemplos se pueden consultar en el trabajo de Ismael Sánchez Bella. Derecho Indiano: Estudios. I: Las Visitas Generales en la América Española, siglos XVI-XVII. Pamplona. Universidad de Navarra, 1991.XI, 357 pp.

${ }^{6}$ David Block, "Treinta años de visitas de indios, una bibliografía anotada". En Anuario 2000 del Archivo y Biblioteca Nacionales de Bolivia. Sucre. p. 578

${ }^{7}$ Woodrow Borah. El juzgado general de indios en la Nueva España. México, Fondo de Cultura económica, $1985.488 \mathrm{pp}$

${ }^{8}$ Maria Rostorowsky y Pilay Remy. Las visitas de Cajamarca 1571-1572. Documentos, Instituto de Estudios Peruanos, Lima, 1992.

${ }^{9}$ Hermes Tovar Pinzón,. "El saber indígena y la administración colonial española: la visita a la provincia de Mariquita de 1559" Anuario Colombiano de Historia Social y de la Cultura, 22, 1995, p.10

${ }^{10}$ John V. Murra, Visita de la provincial de León de Huánuco en 1562: Iñigo Ortiz de Zúnina, visitador. Huanuco. Universidad Nacional Hermilio Valdizán. Facultad de Letras y Educación, 1967-1972. 2v.
} 
etnohistórica como a la determinación de sacar estos documentos de los archivos para que los investigadores le pusieran atención ${ }^{11}$.

En lo que se refiere al estudio de las visitas en Tucumán y Paraguay, se debe destacar el aporte realizado por Gabriel G. Doucet, quien trabajó especialmente estos documentos a partir del análisis pormenorizado de una de las visitas más importantes llevadas a cabo en este territorio, la del oidor Francisco de Alfaro ${ }^{12}$. También abrió caminos en el estudio de la visita del oidor Antonio Martínez Luján de Vargas, tema que fue posteriormente abordado por otros historiadores ${ }^{13}$.

Las visitas fueron una herramienta o estrategia de control del "estado colonial" en las diversas regiones del territorio americano. Los documentos productos de estas visitas coloniales han sido de gran utilidad para los historiadores y etnohistoriadores dedicados al estudio de los grupos étnicos quienes han confiado en la veracidad de la información recogida en estos documentos administrativos.

Hoy en día, buena parte de la historiografía, considera que debe hacerse una lectura más sutil y menos positivista de los documentos de las visitas, que no registrarían un mundo naturalmente "hallado", sino uno dramáticamente "representado". Para esto, se presta atención al aspecto ritual de las visitas, que tenían por objeto evocar la presencia del rey, manteniendo la ficción de un vínculo inmediato y directo entre la corona española y sus vasallos indígenas ${ }^{14}$.

\section{Estructura de las Visitas}

Para José Miranda que ha estudiado las visitas desde el punto de vista de la tributación indígena, se distinguen tres operaciones en este proceso: la visita, para averiguar las posibilidades de los indios; la cuenta para saber el número y la tasación, para fijar la cuantía de los tributos ${ }^{15}$. Estas tres operaciones principales solían ser efectuadas en un acto unitario por la misma persona, cuya comisión recibe el nombre de visita.

En las visitas realizadas a Corrientes, sobre todo en el siglo XVII se distinguen las

${ }^{11}$ David Block, Ob. cit. pp 578.

${ }^{12}$ Gabriel G. Doucet,. "Génesis de una visita de la tierra. Los orígenes de la visita de las gobernaciones de Tucumán y Paraguay por el Licenciado Don Francisco de Alfaro". En Revista de Historia del Derecho. Instituto de Investigaciones de Historia del Derecho. 14, Buenos Aires, 1986. Pág. 123-220

${ }_{13}$ Gabriel G. Doucet. "Introducción al estudio de la visita del oidor Don Antonio Martínez Luján de Vargas a las encomiendas de indios del Tucumán". Boletín del Instituto de Historia Argentina y Americana Doctor Emilio Ravignani. 26. Buenos Aires, 1980. Pág. 205-246. "Los autos del visitador Don Antonio Martínez Luján de Vargas". Revista de Historia del Derecho. Instituto de Investigaciones de Historia del Derecho. 8, Buenos Aires, 1980. Pág 123-154. Judith Farberman. "Indígenas, encomenderos y mercaderes: los pueblos de indios santiagueños durante la visita de Luján de Vargas. (1693)". Anuarios IHES 6, Tandil, Argentina, 1991. p. 43-57.Roxana Boixadós y Carlos Zanolli. La visita de Luján de Vargas a las encomiendas de la Rioja y Jujuy (1693-1694). Estudios preeliminares y fuentes. Universidad Nacional de Quilmes. 2003.

${ }^{14}$ Jorge A. Guevara Gil y Frank L. Salomon. "La visita personal de indios: ritual político y creación del indio en los Andes coloniales". Lima: PUCP-Instituto Riva-Agüero, 1997, p. 48

${ }^{15}$ José Miranda. El tributo indígena en la Nueva España durante el siglo XVI, México, El Colegio, 1952. 
siguientes partes: el recuento de los indios, desde el cacique, los tributarios y sus familias, un cuestionario modelo con preguntas específicas sobre el tributo, la mita, el tratamiento y la doctrina. Un tercer momento estaba constituido por la presentación de agravios ${ }^{16}$.

La encuesta y las respuestas que se daban a los visitantes constituyen la parte más abierta del documento. Aunque los informantes mantienen el enfoque en el texto, a veces el espacio es usado para divulgar detalles interesantísimos sobre la vida cotidiana en el pueblo y el sistema de relaciones vigente entre los indígenas y los feudatarios.

Una de las particularidades encontradas en visitas específicas realizadas en este territorio, como por ejemplo la que realizó el oidor Andrés Garabito de León, es el descargo de los encomenderos que acompaña al expediente de la visita. El oidor daba traslado de los cargos que surgían a partir de las preguntas realizadas y el beneficiario de la encomienda tenía derecho a responder a cada uno de las acusaciones.

En una última instancia se encuentran las sentencias sobre cada uno de los casos, que reflejaban la decisión final del visitador. Cabe destacar que éstas visitas no se realizaban con fines únicamente fiscales, ya que por el caudal de información referida a la vida cotidiana, aspectos del funcionamiento interno de los pueblos de indios, gobierno, iglesia, se puede acceder a detalles que permiten reconstruir en parte otras características del ambiente del territorio en este siglo. Constituyen los preámbulos los poderes otorgados al visitador y los fines de dicha inspección, la selección de los intérpretes y la exhortación a que los indios manifiesten libremente sus quejas.

En el caso de Corrientes el visitador recorrió cada uno de los pueblos que formaban parte de la jurisdicción de la ciudad principal, y realizó una descripción de cada una de las encomiendas a medida que interrogaba a los caciques ${ }^{17}$.

En una primera parte aparecen consignados todos los integrantes de las mismas, nombrando en primer lugar a los tributarios con sus mujeres, hijos y las edades de los mismos. Por último se incluyen a las viudas y huérfanos. Se anota al margen si el varón es reservado, si está ausente, las causas de dichas ausencias, si tiene alguna deficiencia física (ciegos, por ejemplo, o cortos de una pierna es uno de los caso que aparece) ${ }^{18}$.

La segunda parte recoge datos a partir de un cuestionario que se seguía en todas las encomiendas:

-Si cumplían con la mita, por cuanto tiempo.

-Qué trabajos realizaban.

\footnotetext{
${ }^{16}$ Se debe aclarar que esta estructura sólo se pudo encontrar en una de las visitas realizadas a esta jurisdicción, la del oidor Andrés Garabito de Léon, ya que en visitas anteriores del mismo siglo, como la realizada por el gobernador Góngora o Dávila Enríquez, sólo se presentan datos muy generalizados y no se responde a esta estructura. Visita del Oidor Andrés Garabito de León. Archivo y Biblioteca Nacionales de Bolivia. Serie Expedientes Coloniales. EC. 1653.7; 1650.11;1653.11;1653.29. En adelante: ABNB. EC. Este proceso, sin embargo es similar al que se llevó a cabo en la visita del oidor Luján de Vargas. Roxana Boixadós y Carlos Zanolli. Op. Cit.

${ }^{17}$ Este hecho de recorrer todos los pueblos, lo destacamos especialmente porque en otras visitas como por ejemplo la del oidor Luján de Vargas al Tucumán, el visitador no se trasladó de pueblo en pueblo. Roxana Boixadós y Carlos Zanolli. Op. Cit. Pág.23

${ }^{18}$ Visita del oidor Andrés Garabito de León. ABNB. EC. 1653.7
} 
-Qué tratamiento les ofrecía su encomendero.

-Si cumplían con la doctrina.

En éstas respuestas se plasmaban temas relacionados con diversos aspectos de la vida de la reducción: tierras, labranzas, ganados, relaciones personales entre encomenderos y encomendados, datos que, sin lugar a dudas constituyen un valioso caudal para estudios desde diversos enfoques.

El tercer momento que se distingue tiene que ver con la presentación de los agravios. Los indígenas exponían sus quejas, relataban sus disconformidades con el tratamiento o accionar de los encomenderos.

De esta manera finalizaba la visita en lo que se refiere al aspecto relacionado con los indígenas y su participación en el proceso. Posteriormente el visitador daba traslado de los cargos a los encomenderos denunciados y esperaba las respuestas de los mismos frente a las acusaciones. En una de las visitas, nos encontramos con el proceso completo, ya que se adjuntaron dichos descargos y la sentencia final del visitador, con multas y gravámenes para la corona.

Las visitas pertenecientes a la jurisdicción de Corrientes se encuentran en general en el Archivo de dicha ciudad (sobre todo las del siglo XVIII,) como así también en el Archivo General de la Nación. Sobre el siglo XVII existe abundante información en el Archivo de la ciudad de Sucre, además de visitas, datos detallados sobre este territorio que en este período pertenecía a la Audiencia de la Plata.

\section{Visitadores, visitas y obstáculos}

Estaba legislado por cédulas que fuera el oidor más antiguo quien comenzara la ronda de visitas y que a él siguieran los demás. El oidor- visitador recibía 200.000 maravedíes de costa anual y no podía llevar consigo familiares ni criados, con objeto de evitar gastos. El escribano que lo acompañaba percibía su paga de las penas de cámara impuestas.

En el caso de Corrientes, fueron muy pocos los oidores que realizaron visitas a la jurisdicción, durante el siglo XVII: el oidor Andrés Garabito de León (1653) y el oidor Juan Blázquez de Valverde (1673) ${ }^{19}$, ambos pertenecientes a la Audiencia de la ciudad de La Plata.

Las visitas realizadas en la centuria siguiente fueron llevada a cabo por los tenientes de gobernadores de la ciudad y tuvieron características muy diferentes a las realizadas durante el siglo XVII, ya que sólo ofrecen detalles cuantitativos sobre la población indígena.

Con respecto a la frecuencia de las visitas, se debe aclarar que las mismas no se realizaron periódicamente en esta región, sobre todo en el siglo XVII. Indudablemente las incomodidades que implicaba concretarlas, largos viajes a caballo por caminos peligrosos, condiciones climáticas desfavorables que más de una vez retrasaron el viaje, y hasta enfermedades que podían atacar al visitador en medio de la travesía fueron las características

\footnotetext{
${ }^{19}$ De la visita del oidor Blázquez de Valverde tenemos informes de la realización de la misma en las Actas Capitulares de la ciudad de Corrientes, pero no sabemos donde se encuentra el documento de dicha visita.
} 
comunes en estos derroteros. La visita del oidor Garabito, se retrasó en varias oportunidades por lluvias permanentes que impedían seguir con el recorrido, y hasta por una enfermedad que lo atacó severamente y lo obligó a guardar reposo por algún tiempo ${ }^{20}$.

La falta de oidores también podía entorpecer la frecuencia de las visitas. Aunque en teoría eran cuatro, con frecuencia faltaba uno, por defunción o traslado. De los restantes, dos debían asistir al despacho de los pleitos de la Audiencia para poder dictar sentencia, y sólo el otro podía salir de visita ${ }^{21}$.

Es de suponer, que los obstáculos para la realización de éstas visitas no sólo partían de los visitadores, sino también de los visitados. Indudablemente las noticias de la presencia de un oidor de la Audiencia con fines de control infundía temor sobre todo en el grupo de encomenderos que debían presentar títulos, confirmaciones y demostrar el cumplimiento de las ordenanzas ${ }^{22}$. En Corrientes no se encontraron datos de oposición por parte de funcionarios ni encomenderos, aunque sin lugar a dudas la llegada habrá provocado nerviosismo, se pueden observar en las actas capitulares grandes preparativos de recibimiento a los mismos.

\section{Las Visitas realizadas a Corrientes entre los siglos XVII-XVIII}

Para realizar un análisis institucional, demográfico y social de las encomiendas de Corrientes en los siglos XVII-XVIII, es posible tomar como fuentes, una serie de visitas realizadas a esta jurisdicción como así también padrones elaborados en ocasiones por funcionarios locales, fundamentalmente, Tenientes de Gobernadores ${ }^{23}$. Es importante destacar que el interés fiscal primaba en estos documentos, por eso la información específica que ofrecen es lo referido a la población tributaria, de todos modos algunas fuentes son riquísimas en otros aspectos referidos a la aplicación del régimen y a la vida del indígena, las mismas se irán describiendo a continuación.

Los detalles en la información sobre la población nos permiten realizar un seguimiento bastante significativo a través de los dos siglos de la población encomendada. Intentaremos a continuación ofrecer una lista de visitas y otras fuentes que nos permiten abordar el estudio de los indígenas que vivían en los pueblos en esta región, para después ingresar en los problemas que se nos presentaron al utilizarlas.

\footnotetext{
${ }^{20}$ ABNB.EC.1653.29. EC. 1653.7

${ }^{21}$ Frecuentemente no se dejaba a la Audiencia en esta situación, pues cualquier indisposición de uno de los dos oidores paralizaba la actividad del tribunal. En Nueva Granada, por ejemplo, por este motivo y por el volumen de negocios, se aumentó el número de oidores a seis, pero creando dos salas de Audiencias, con lo que la posibilidad de enviar un visitador seguía siendo escasa. Julián Ruiz Rivera. Op cit. p. 6

${ }^{22}$ Se registran casos de tenaz oposición por parte de gobernadores, contra quienes no iba dirigida la visita. En 1602 consiguió el gobernador de Muzo, Nuño de Solís, una cédula que prohibía la visita en su territorio. El gobernador había falseado de tal forma las noticias que el rey ordenó que no se continuase la visita, que de hecho nunca se había iniciado. Ibídem

${ }^{23}$ Cabe aclarar también que existe un importante caudal de documentos en los archivos de Corrientes, Buenos Aires y Sucre referidos al gobierno, a la justicia, actas capitulares, que son significativos para el estudio de la región. No se tendrán en cuenta en este trabajo por tratarse específicamente el tema de la visitas como fuentes.
} 


\section{1-El primer reparto de encomiendas:}

Los primeros datos que se recogen sobre la población encomendada son los del primer reparto de encomiendas realizado el día 2 de Noviembre de 1588, apenas fundada la ciudad por el Capitán General y Justicia Mayor Alonso de Vera y Aragón. En este documento no se expresan números concretos, sólo se mencionan los nombres de los encomenderos y las naciones que se les fueron concediendo. Este primer reparto se extendió hasta 1593. Hernando Arias de Saavedra hizo lo mismo en 1598. De acuerdo con los datos que ofrecen las fuentes, 61 encomiendas fueron adjudicadas por autos del 2 de Noviembre de 1588, 3 en 1589, 26 en 1590. 12 en 1592, 17 en 1593, 3 en 1598; ascendiendo el total de ellas a 122. Incluidos el Rey y el adelantado, "eran 104 los dueños de más de doscientas tribus" 24 .

\section{2-Visitas de los gobernadores Góngora (1622) y Dávila Enríquez (1635)}

La visita del gobernador Diego de Góngora realizada entre 1620-1622 se constituye en una interesante fuente, aunque los datos que brinda son generalizados. En su recorrido visitó todos los pueblos de Corrientes, ofreciendo en sus informes un panorama descriptivo de las reducciones existentes en el territorio como así también de sus habitantes y costumbres. Complementan el informe, detalles sobre la estructura edilicia de los pueblos, iglesias, ornamentos y casas de los indios. Se presentan también totales de población femenina y masculina que son los únicos datos demográficos específicos de principios del siglo XVII-

La visita del Gobernador Pedro Dávila Enríquez aportó solo algunas generalidades sobre la ciudad de Corrientes, describió la pobreza de la misma sin datos cuantitativos específicos sobre la población nativa. Sólo se mencionan "algunos yndios...que dicen son muchos y hablan diversas lenguas"... ${ }^{25}$

\section{3-Visita del oidor Andrés Garabito de León (1653)}

Esta visita se constituye en la primera fuente de tipo protoestadística que se ha rescatado del siglo XVII, con detalles que permiten conocer el estado de las reducciones de este territorio así como la situación del indígena, inserto en el régimen de encomiendas.

Esta visita, presenta un minucioso registro: aporta datos demográficos, pleitos por títulos de encomiendas, medidas tomadas por el visitador, además de permitir conocer información sobre la vida cotidiana, aspectos sociales y económicos del régimen de encomiendas aplicado a estos centros urbanos coloniales y pueblos de indios.

La visita de Garabito de León responde al interés de la corona de conocer el estado de los tributarios en cada una de las encomiendas. Se atienden especialmente las cuestiones

\footnotetext{
${ }^{24}$ No tenemos precisiones acerca del número de personas que conformaban cada tribu. "Primer reparto de indios en encomiendas en Corrientes". En: Revista de la Biblioteca Nacional de Buenos Aires, Tomo 25. Año 1865 pp. 166-175

${ }^{25}$ Vista de Diego de Góngora y Pedro Dávila Enríquez. En: Miguel Cervera. Historia de la ciudad y provincia de Santa Fe.1573-1853. Santa Fe. La Unión, 1907. vol 1. p. 77-90
} 
relacionadas con el tratamiento y el cuidado del indígena así como el estado espiritual de la población encomendada. El oficial se interesó por verificar el cumplimiento de la reglamentación sobre encomiendas, vigente en ese momento: las ordenanzas de Alfaro.

De todas las visitas analizadas, la visita de este oidor es la más rica y completa, única por sus características y de un valor realmente importante. En su recorrido visitó Itatí, Santiago Sánchez, Santa Lucía, Ohoma y los indios originarios de la ciudad de Corrientes.

El original de este documento se encuentra en el Archivo y Biblioteca Nacionales de Bolivia, en la ciudad de Sucre.

\section{4-Padrón de vecinos encomenderos de indios existentes en San Juan de Vera de las Siete Corrientes (1673).}

Como su nombre lo indica este es un padrón de vecinos encomenderos de la ciudad de Corrientes, cuyo original se encuentra en el Archivo General de Indias. Lo realizó Luis Toñanes, lugarteniente de gobernación, Justicia Mayor y capitán en la ciudad de Corrientes por orden del gobernador de las provincias del Río de La Plata Don José Martínez de Salazar para "...tener noticia individual de las encomiendas de indios y de quién las goza..."26

Aporta los nombres de los encomenderos, el número de encomiendas que tenían a su cargo, en qué vida se encontraban haciendo uso de su encomienda y el número de tributarios y reservados. Se registran a los naturales de Itatí, Santiago Sánchez, Candelaria de Ohoma y Santa Lucía. No se consignaron datos referidos a las familias de los registrados.

\section{5-Visitas de 1717-1719 y 1721.}

En éstas visitas de características muy similares, llevadas a cabo por la misma persona, el Teniente de Gobernador de Corrientes Francisco de Noguera Salguero, se tuvo especial cuidado en registrar a la población encomendada. En la primera llevada a cabo en 1717 se registraron a los varones tributarios con sus mujeres y sus hijos varones, pero no se tuvieron en cuenta a las hijas mujeres de cada matrimonio, lo que deja muy claro el interés fiscal de la misma. La visita de 1719 se realizó, según se explica en la fuente por el azote de una gran peste, lo que hizo necesario un nuevo registro actualizado debido a las muertes acontecidas.

La visita de 1721 es un poco más completa en cuanto a los datos de los habitantes de los pueblos ya que se registran a las niñas, grupo que no se había tenido en cuenta anteriormente. En todas ellas también el funcionario se interesa por otras cuestiones como el tratamiento que reciben de sus encomenderos y se les comunicó a los indios la posibilidad de emitir quejas. El tema de la doctrina también está presente, para verificar el cumplimiento de la misma. Los originales de estos documentos se encuentran en el Archivo General de la Nación.

${ }^{26}$ Padrón de vecinos encomenderos de indios existentes en San Juan de Vera de las Siete Corrientes. Archivo General de Indias. Sevilla. Contaduría. 1877. 
Existen otras visitas que hemos decidido no tratar en este trabajo de acuerdo con nuestro recorte temporal. Cabe aclarar que en el primer tercio del siglo XVIII desaparecen los pueblos de Candelaria de Ohoma y Santiago Sánchez, permaneciendo sólo Santa Lucía e Itatí. De todos modos sólo esta última fue motivo de controles permanentes ${ }^{27}$.

\section{Posibilidades y limitaciones de las visitas como fuentes para el estudio de la encomienda en Corrientes}

La encomienda como institución fue cuestionada desde los primeros tiempos por el sometimiento del indígena a trabajos duros e inhumanos y por el abuso de los encomenderos.

La corona encontró entonces en el régimen de visitas, realizadas entre los siglos XVI y XVIII, una forma de control por la cual recibía información a partir del trabajo de los visitadores, los que a su vez debían ser confiables y eficientes para elaborar los informes adecuados y aplicar de acuerdo con sus atribuciones las medidas necesarias ante las irregularidades presentadas.

Nos interesa profundizar en las posibilidades y las limitaciones con las que se encuentra el historiador al utilizar este tipo de fuentes y específicamente el aporte de las mismas para el estudio de algunos aspectos de la historia colonial correntina, en este caso de la encomienda de indios.

Nos concentramos en este caso específico, sobre todo en la de 1653 y en las primeras realizadas en el siglo XVIII.

\section{a) La población encomendada}

Las visitas realizadas a Corrientes nos presentan información específica sobre la población indígena que habitaba en los pueblos de indios y en la ciudad como originarios o yanaconas residentes en las casas o chacras de los encomenderos ${ }^{28}$. En este caso tendremos en cuenta sólo a los que vivían en pueblos. Los españoles aparecen en la documentación eventualmente a partir de las relaciones con los indígenas o por ser los feudatarios de las encomiendas, pero nunca a manera de censo o padrón de pobladores. Claro está que su lugar de residencia era en las ciudades y no en los pueblos de indios ${ }^{29}$.

Una de las preguntas más frecuentes que nos hicimos es hasta que punto los datos cuantitativos representaban la realidad demográfica de este territorio. Nuestra experiencia personal y los planteos historiográficos actuales, con respecto a la utilización de estas fuentes, nos llevan a utilizar estos datos con mucho cuidado y a encontrar respuestas o

${ }^{27}$ Existen otras visitas de los años: 1759,1761, 1769, 1772, 1782, 1789, 1795 obrantes en el Archivo histórico de la Provincia de Corrientes.

${ }^{28}$ Con respecto a los denominados indios originarios, se debe aclarar que en los documentos que hemos trabajado para Corrientes, Santa Fe y Paraguay aparece este término para designar a los indios yanaconas que vivían con sus encomenderos en sus chacras o en las ciudades, situación diferente a otros territorios.

${ }^{29}$ Es interesante destacar, con respecto a los habitantes de los pueblos de indios que en las visitas del siglo XVII, no se realiza ninguna mención a la presencia de otros grupos como mestizos o mulatos. En los padrones del siglo XVIII ya se lo encuentra mencionados, pero en muy escasa cantidad. 
causales posibles de los comportamientos demográficos resultantes de la lectura de dichos registros. Desde el principio entendimos que nuestros datos no ofrecen "seguridad" pero a la vez, en el caso de Corrientes, son casi las únicas fuentes, para el XVII por ejemplo, que nos permiten aproximarnos a un conocimiento más profundo de estas poblaciones.

Uno de los primeros problemas que se nos presentaron tiene que ver con el estudio de las familias. En los documentos aparecen registradas familias nucleares, situación que nos facilitó la posibilidad de agruparlas y hacer una clasificación propia de acuerdo con los datos que se nos presentaban ${ }^{30}$. Tuvimos en cuenta la agrupación de los individuos según un lazo de parentesco, de sangre o por alianza, o sea un criterio familiar.

En general, en los documentos se registraron familias nucleares constituidas por padre, madre e hijos y viudos y viudas con hijos. Como nos planteamos una relación permanente con la antropología para dar respuesta a algunos de nuestros interrogantes, entendemos que las familias nucleares que aparecen inscriptas se presentan de esta manera de acuerdo con el criterio del visitador que es quien registra a los tributarios con sus mujeres e hijos. En la práctica las redes familiares, sin lugar a dudas, eran mucho más complejas. Sabemos que la familia guaraní al igual que la chaqueña es extendida. Además, siguiendo el criterio del visitador, algunos habitantes nos quedan fuera de toda agrupación familiar, los huérfanos, los viudos sin hijos y en ocasiones quienes aparecen como solteros, por ejemplo aparecen incluidos al final, luego del registro de todas las familias. En algunos casos los ubicamos dentro del grupo de los solitarios, pero sabemos que estaban agregados en otras familias.

\section{Figura 1}

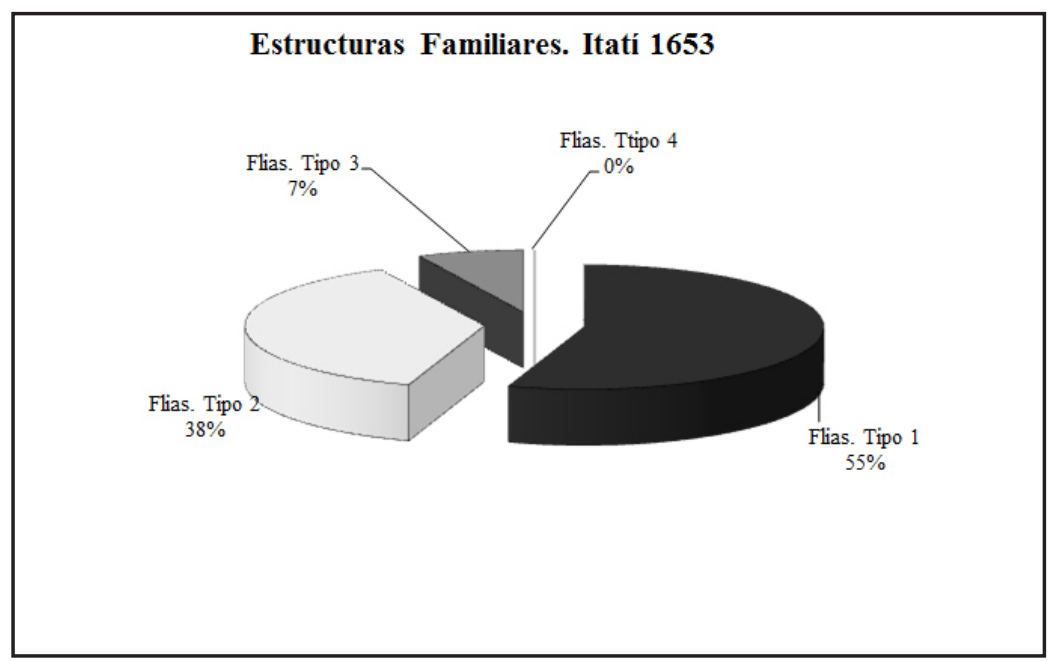

${ }^{30}$ Se tuvieron en cuenta a las familias de acuerdo con los datos que ofrece el registro de la visita, analizados a partir de la clasificación que realiza Peter Laslett. "La familie et le ménage: approches historiques" Annales Economies, Sociétés, Civilisations, 1972,4-5, pp. 847-872 
A modo de ejemplo presentamos las estructuras familiares en Itatí. Se ha realizado una clasificación de la siguiente manera:

Familias Tipo 1: Parejas con hijos

Familias Tipo 2: Parejas sin hijos.

Familias Tipo 3: Viudos con hijos

Familias Tipo 4: Solteros con hijos ${ }^{31}$

Por un lado presentamos los resultados que nos ofrecen las fuentes (familias identificadas claramente como nucleares) pero por otro lado debemos entender a estas familias como una configuración relacional. Las viudas, probablemente hayan sido, en algunos casos, también abuelas, los huérfanos no vivían seguramente solos. Estos integrantes que no se incluyen dentro de la familia nuclear, indudablemente tenían su espacio y se relacionaban con las familias formadas por padres e hijos identificados claramente en los documentos. Es necesario comprender que cuando se ausentaban los varones a cumplir la mita o eran llevados a otras ciudades, en ocasiones sin posibilidades de regresar, cuando las mujeres cumplían tareas de servicio doméstico o de hilados para sus encomenderos en las casas de éstos, se configuraban en la práctica relaciones diversas entre los habitantes del pueblo que hacían que los niños que quedaban solos quizás eran cuidados por tías, abuelas, creando así redes que no pueden ser visualizadas en las fuentes pero que deben ser percibidas por quienes analizamos esta realidad ${ }^{32}$.

Siguiendo con los problemas que se nos presentaron con las familias, consideramos que todo análisis puede ser relativo en casos como por ejemplo la cantidad de hijos. En la visita de 1653 se nos presenta también la posibilidad de conocer en detalle el número de hijos que tiene cada familia.

\section{Cuadro 1}

Parejas según número de hijos en Itatí. 1653

\begin{tabular}{|c|l|l|l|l|l|l|l|}
\hline Encomiendas & Filas & M/s Hijos & $\begin{array}{l}\text { M } \\
\mathbf{c} / \mathbf{1} \text { Hijo }\end{array}$ & $\begin{array}{l}\text { M c/2 } \\
\text { Hijos }\end{array}$ & $\begin{array}{l}\text { M c/3 } \\
\text { Hijos }\end{array}$ & $\begin{array}{l}\text { M c/4 } \\
\text { Hijos }\end{array}$ & $\begin{array}{l}\text { Viudos } \\
\text { c/Hijos }\end{array}$ \\
\hline 16 & 196 & 74 & 46 & 39 & 17 & 6 & 14 \\
\hline
\end{tabular}

En el cuadro 1 se pueden observar, el número de encomiendas existentes en el pueblo, el número de familias y también se consignan los matrimonios con el número de hijos, se tienen en cuenta también viudos y viudas con hijos. La particularidad radica en el reducido número de vástagos que tiene cada familia, que no sobrepasa la cantidad de cuatro. No se ha encontrado en la documentación una sola familia con cinco o más hijos. El promedio de hijos por familia es de 1,1. Es importante destacar también el alto porcentaje de matrimonios sin hijos. Ejemplos de esto, representa el caso de la encomienda de Pedro

${ }^{31}$ Si bien no se han encontrado casos del Tipo 4, se tuvieron en cuenta para la clasificación, porque esta categoría aparece en los padrones del siglo XVIII.

${ }^{32}$ Haciendo una lectura entre líneas de las fuentes, podemos encontrar relaciones de parentesco más profundas, ya que en algunos casos se hacen referencia a hermanos, cuñados, hijos, etc. pero no es lo común. 
de Aguiar que sobre un total de 23 familias, hay 12 matrimonios sin hijos, o el caso de la encomienda de Ana de Meza, en la cual de 17 familias hay nueve matrimonios sin hijos. El $38,3 \%$ aproximadamente de las familias no tienen hijos, el 23,4 \% tiene un hijo; el 19,8\% tiene dos hijos, el 8,67 \% tiene tres hijos y el 3,06 \% tiene cuatro hijos.

Establecer las probables causas de esta situación, se transforma en tarea difícil ya que la documentación se reduce solo a dar la información que presentamos, aunque la lectura de la misma puede revelar datos interesantes.

Nos referimos específicamente a algunas referencias que surgen de las preguntas del visitador: los indígenas hacen alusión en varias oportunidades a la "gran peste" que había azotado a la región tiempo atrás y provocó la muerte de gran cantidad de habitantes. Es probable entonces que haya habido un gran índice de mortalidad, aunque no se establece claramente cual fue la enfermedad ni tampoco se tienen datos acerca de la cantidad de muertes provocadas por la misma. En las actas del cabildo de la ciudad de Corrientes aparece esta peste mencionada en el año $1652^{33}$ en el documento de la visita se menciona fugazmente la viruela y se hace referencia "a los estragos que causó la peste" 34 estos son los únicos datos que tenemos para fundamentar este hecho.

La escasa cantidad de hijos en cada una de las familias se puede relacionar con algunas circunstancias: a) probable mortalidad en infantes, b) uniones recientes, c) ausencias prolongadas de los varones, d) Forma en que el visitador recogía los datos, e) Subregistros.

a) Sobre mortalidad en la infancia no se tienen datos concretos que fundamenten esta posibilidad, aunque en el documento se mencionan algunos niños muertos en la peste. Esta circunstancia se podría explicar también a partir del pequeño porcentaje de viudos y viudas (alcanzan al 3\%) y de los huérfanos (representan el 4\% aproximadamente de la población), estos índices menores, hacen presumir que la peste no atacó a los mayores, aunque tampoco se tienen datos de mortalidad en niños.

b) Este hecho puede encontrar relación también con uniones recientes, considerando que los matrimonios se realizaban casi en la adolescencia, probablemente en el momento que llegó el visitador había muchas parejas recién formadas que todavía no habían generado descendencia.

c) También se intentó relacionar este hecho con las ausencias de los maridos, por ello, se comprobó el número de mujeres con maridos ausentes, buscando causales de la poca cantidad de hijos en esta circunstancia. De las mujeres presentes en el pueblo el $16,8 \%$ tiene sus maridos ausentes. De este total de mujeres con ausencia de sus maridos el $40,6 \%$ no tiene hijos, el 37, 5\% tiene un hijo y el 18,7\% tiene dos hijos. Se debe tener en cuenta que por lo general los alejamientos de los hombres duraban meses. Estas ausencias estaban relacionadas con el cumplimiento de la mita que alejaba a los varones dos meses al año (siempre que se cumplieran las ordenanzas) y con los llamados "mandamientos", que

\footnotetext{
${ }^{33}$ Academia Nacional de la Historia. Actas Capitulares de la ciudad de Corrientes. Advertencia de Ricardo Levene. Introducción de Hernán Gómez. Buenos Aires.1941-1946. Tomo II Pág. 308

${ }^{34}$ Visita a Santiago Sánchez. ABNB. EC. 1653.16
} 
eran solicitudes de gobernadores y funcionarios de cierta cantidad de indios para realizar distintas tareas en la ciudad, en las chacras, o en otras ciudades para lo que tenían que viajar.

Estos mandamientos pesaban más sobre las reducciones de franciscanos, por su cercanía a las ciudades y los sacerdotes actuaban en ocasiones como moderadores de este sistema, quejas y solicitudes de estos últimos sobre estos pedidos de indios quedaron reflejadas en numerosos documentos. Las reducciones de jesuitas estaban más alejadas de las grandes ciudades, por lo que los funcionarios sólo se atrevían a solicitar prestaciones militares, y si bien esto significaba destinar hombres, la formación del contingente se prorrateaba entre los 20 o 30 pueblos, disminuyéndose así los efectos negativos de esa leva en la vida de la población ${ }^{35}$.

d) Otra respuesta tiene que ver con la forma en que el visitador recogía los datos, como no se establecen las edades de las parejas sin hijos, no se sabe si eran jóvenes o adultas, es probable que las parejas mayores que tenían todos sus hijos casados aparezcan registradas como "sin hijos", lo que no quiere decir que nunca los hayan tenido sino que en ese momento sus hijos ya habían conformado otro grupo familiar.

e) La presencia de subregistros es necesario tener en cuenta. Más allá de los detalles descriptivos de la vida de las reducciones y otros factores que se reflejan, estas visitas detienen su mirada en el conjunto de varones tributarios y próximos a tributar, por lo que la mujeres, niñas, viudas pasan a un segundo plano y seguramente no se registraron en su totalidad. Por eso es necesario contemplar a los subregistros como una de las variables explicativas al analizar los datos cuantitativos que ofrecen estas fuentes.

No obstante, consideramos que estos documentos, si bien son de tipo protoestadísticos y pueden tener importantes subregistros, constituyen una fuente básica para el estudio de la población en estos territorios.

Siguiendo con el tema de las familias, hay otros datos que se presentan confusos con respecto al tema de los hijos, por ejemplo. Se han encontrado algunas referencias acerca de que a "los hijos de los hermanos llaman hijos". Esto nos lleva a pensar que en ocasiones los hijos que se nombran pueden llegar a ser sobrinos o tener otro parentesco.

Por otra parte no se pudo establecer, si cada una de las familias vivía en una casa o rancho, o si en una casa vivía más de una familia nuclear. En el documento no se ofrecen detalles sobre estos aspectos. Varias familias nucleares se agrupaban constituyendo una parcialidad, al mando de un cacique, quien tenía a su cargo la distribución de los turnos para cumplir la mita, entre otras actividades, es probable que vivieran varias familias juntas ${ }^{36}$.

En el momento del registro del oidor Garabito de Léon, por ejemplo la comunidad estaba constituida por familias pequeñas, característica que se mantendrá en períodos posteriores. El promedio de integrantes de las mismas es de 3,09 individuos ${ }^{37}$.

\footnotetext{
${ }^{35}$ Ernesto Maeder. "Asimetría demográfica entre las reducciones franciscanas y jesuitas de guaraníes". En Revista Complutense de Historia de América, núm.21. Universidad Complutense. Madrid, 1995. p. 82-83.

${ }^{36}$ Visita al Capitán Mateo González de Santa Cruz. ABNB. EC. 1653.7

${ }^{37}$ La familia en las Misiones Jesuíticas estaba integrada, termino medio, por 4,4 personas; los valores extremos
} 
Otro aspecto interesante de analizar tiene que ver con los jóvenes y niños. Siguiendo con el ejemplo de la visita de 1653, se tomó el grupo menores de 17 años (aunque se han registrado muy pocos jóvenes mayores de 15 años) no porque no existieran sino porque probablemente los que tenían esa edad aparecen en el expediente como casados a cargo de una familia y no se mencionan sus edades. Este dato nos lleva a pensar también que no se respetaba la edad de 18 años para comenzar a tributar.

El grupo de menores de 17 años representa el 40,5\% de la población presente.

En el expediente se especifican claramente las edades de los niños, con excepción de los menores de dos años, donde no se menciona tiempo de vida sino que se establece el mote "al pecho" o "de teta". Recién a partir de los dos años se menciona exactamente la edad de cada niño o niña. Se detallan claramente los datos acerca del sexo y edad, suponemos que con el objeto de informar a la corona cuantos tributarios tendría en años subsiguientes.

Figura 2

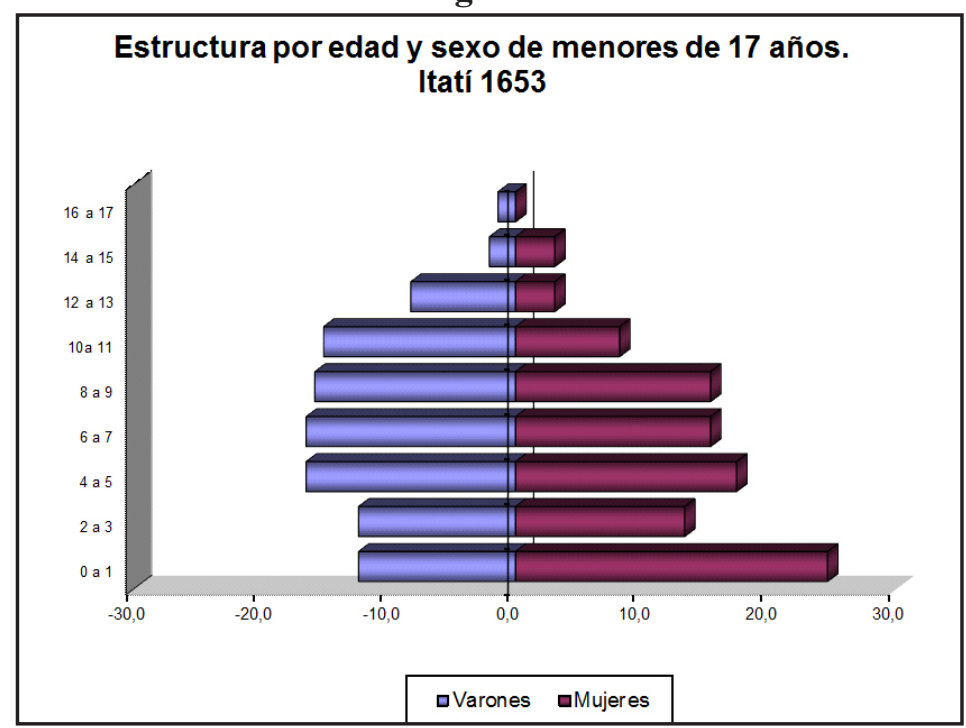

En la figura 2 se tuvo en cuenta la estructura por edad y sexo de menores de 17 años en el momento de la visita de Garabito de León.

En este sentido es necesario aclarar nuevamente que, si bien las edades están discriminadas, fueron determinadas por el visitador. Además se debe entender que todo estudio en este sentido puede ser relativo, ya que nos encontramos que en ocasiones se consigna la edad aproximada y no la "real". Por ejemplo en la encomienda de Nicolás de Villanueva se registra a un indio "... Juan que tiene toda la cabeza blanca parece ser de edad de 70 años". ${ }^{38}$

oscilan entre 3,9 y 5,0. Ernesto Maeder y Alfredo Bolsi. "Evolución y características de la población guaraní de las Misiones Jesuíticas. 1671-1767”. Historiografía 2. Buenos Aires.1976. Pág.126

${ }^{38}$ ABNB. EC.16353.7 
Es este sentido consideramos que los registros de edades no son suficientemente confiables. Esta hipótesis se basa en dos aspectos: en primer lugar es sabido que los grupos indígenas chaqueños y guaraníes no poseen en su estructura lingüística una percepción numérica cardinal, lo que impediría contar con precisión las edades; y en segundo lugar no se tienen datos acerca de los registros de bautismo que podrían objetivar el proceso de registrar las edades de los niños. Es mucho más verosímil entender que la estructura poblacional reflejada en los datos del visitador, no sea lo suficientemente confiable en lo que a las edades se refiere. Eso explicaría las desigualdades demográficas que se observan en las pirámides de estos pueblos.

En las edades de 0 a 1 años se observa una mayor cantidad de niñas, pero en los niveles superiores ya se equilibran los porcentajes entre varones y mujeres. Se observan claramente las posibles consecuencias de la viruela en la población infantil entre los dos y los cinco años. Probablemente esta enfermedad también provocó mortalidad en recién nacidos o por nacer y es eso lo que se evidencia en varones de 0 a 2 . Hay un repunte entre los cinco y los seis años y luego una descenso aunque no llega a los valores de los grupos más afectados.

Al observar estas pirámides ${ }^{39}$ con tan pocos niños relacionamos inmediatamente el tema con la poca cantidad de hijos en las familias, al que ya hicimos referencia. Sabemos que estos grupos indígenas tienen algunas prácticas sobre las que queremos abrir algunos interrogantes.

Desde el punto de vista cultural, nos encontramos ante pueblos aborígenes que mantenían aspectos propios de su vida de nómada o seminómada anterior. Desde esta perspectiva es interesante reconocer que el impacto de esta cultura en la conformación de las estructuras familiares es determinante. Las familias poseían un número escaso de hijos ya que esa es una de las características de las poblaciones nómadas de cazadores recolectores. En este sentido nos preguntamos, en nuestro permanente diálogo con la antropología, si las mujeres tenían costumbres abortivas con hierbas. Una de las características de los pueblos cazadores-recolectores es también la eliminación de niños porque no les permitían una movilidad geográfica adecuada y se les restringían considerablemente los víveres en sus migraciones. Sabemos además que algunos grupos practicaban por ejemplo la eliminación de uno de los niños cuando nacían gemelos. Otro elemento a tener en cuenta era la capacidad biológica de procrear unida a las características alimentarias de estos pueblos y a los condicionantes ambientales de la región ${ }^{40}$. El tipo de alimentación indudablemente cambió en las poblaciones reducidas. La práctica de la agricultura les permitió modificar su alimentación a base de frutas, carnes y peces por otra a base de maíz, con el detrimento proteico que este cambio significó. A lo que seguramente habrá que sumar la incomodidad que sentían ante la nueva forma de vida, que los obligaba a trabajar en actividades desconocidas hasta el momento y con un sometimiento importante hacia sus encomenderos.

${ }^{39}$ Hablamos de pirámides porque en los otros pueblos se dan circunstancias muy parecidas.

${ }^{40}$ Alfred Metraux. Estudios de Etnografia chaquense. Anales del Instituto de etnografía americana. Universidad Nacional de Cuyo. 1944. Tomo V 
Todos estos factores sumados al alejamiento de los maridos por causa de la mita o los trabajos para los encomenderos incidieron indudablemente en la tipología de esta población a mediados del XVII.

En los pueblos de Santiago Sánchez y Santa Lucía se da una situación muy parecida a la de Itatí, para la misma época, con respecto los niños y jóvenes. Ambos en la frontera y habitados por grupos nómadas con pocas posibilidades de adaptarse a la situación de reducción e insertos en un sistema de trabajo con características muy diferentes a la caza y recolección a las que estaban acostumbrados.

Queremos orientar el análisis de la población hacia los efectos de la encomienda Consideramos que las características de la población encomendada, son el resultado de este sistema socio-laboral impuesto desde España. Se conformó en ellas un micromundo donde los varones eran sacados de sus lugares de origen, con pocas posibilidades de regresar, las mujeres eran abandonadas y morían en cantidades importantes por diversos factores: parto, ya que se casaban a edades muy tempranas, a veces cuando recién empezaban su etapa reproductiva, también mueren de enfermedades como la viruela.

Por último no queremos dejar de lado un elemento decisivo en esta región: el estado permanente de guerra en que se encontraban inmersos. Esto también sería una causa determinante en la conformación poblacional de los pueblos de frontera.

Por ello nos planteamos algunos interrogantes: ¿El sistema social y de trabajo impuesto por los españoles en las reducciones correntinas con la práctica de las encomiendas, configuró un espacio de destrucción demográfica paulatina para el indígena que las habitaba? Los números de alguna manera nos están indicando éstas líneas a seguir. De hecho los pueblos en el primer tercio del XVIII desaparecen. Este es uno de los puntos sobre el que seguiremos profundizando en nuestros trabajos, siguiendo la evolución de los pueblos hasta sus destrucciones y las consecuencias de las mismas.

Es muy conocido el exhaustivo trabajo de historiadores sobre el impacto de la encomienda, la explotación del indio, enfermedades y muertes por causas de dicha explotación, pero quizás nuestro aporte esté orientado a entender a este régimen aplicado en una franja marginal del Imperio español como provocador de un nuevo sistema social indígena, demoledor en cuanto a las posibilidades de crecimiento poblacional y con pocas posibilidades de subsistencia.

En esta etapa final del siglo XVII la utilización de la mano de obra indígena de estos pueblos por parte de los funcionarios fue acrecentándose, hasta ser utilizada incluso en mayor medida que por sus propios encomenderos. En 1663 se publicó en la Reducción el auto que con fecha 19 de Mayo de 1663 expidió el Obispo Fray Cristóbal de Mancha y Velazco, sobre "la buena correspondencia y caridad que debía existir entre los curas doctrineros y los tenientes de gobernador de Corrientes, declaraba que los primeros de ninguna manera, se entremetiesen en la distribución y repartición de los indios y que su única función era la enseñanza de la doctrina"41. Este tipo de ordenanzas intentaban detener 
las continuas intervenciones de los sacerdotes en la aplicación de mandamientos ejecutados eventualmente por los funcionarios ${ }^{42}$.

En este período también fue notoria la prestación de indios de la reducción para las guerras que hacían los españoles. En 1672, temiéndose un ataque al Puerto de Buenos Aires por ingleses y franceses, a los que se atribuía propósitos de conquista, con el fin de cortar toda comunicación comercial del Perú con España, el gobernador Maestre de Campo Don José Martínez de Salazar dispuso que se preparasen para combatir las ciudades a su mando. El tercio correntino comprendió además de cien soldados blancos, ciento cincuenta indios de los cuáles ochenta eran de Itatít ${ }^{4}$. Cabe señalar también que se pusieron en pie de guerra las canoas de la reducción, que frecuentemente eran utilizadas para defensa de Corrientes. Tenía entonces Itatí unos trescientos indios aptos para llevar las armas ${ }^{44}$.

\section{b) Evolución de la población encomendada siglos XVII principios del XVIII}

Las fuentes demográficas contenidas en las visitas cuentan con limitaciones, por un lado por ser cifras de población estática, analizada en un momento dado, y por otro por ser elementales, vertidas según el simple criterio fiscal para los tributos.

\section{Cuadro 2}

Población en las encomiendas de Itatí

\begin{tabular}{|l|c|c|c|c|c|c|c|}
\hline Visita Año & Tribut. & Muj. & Niños/as & Reserv. & Huérf. & Ausent. & Total \\
\hline 1653 & 127 & 190 & 218 & 43 & 28 & 80 & 606 \\
$1673^{45}$ & 243 & & & 13 & & & 256 \\
1717 & 166 & 254 & 207 & 121 & 43 & 11 & 791 \\
1719 & 96 & 114 & 50 & 55 & 59 & 1 & 374 \\
1721 & 109 & 202 & 166 & 47 & 48 & 23 & 572 \\
\hline
\end{tabular}

\section{Cuadro 3}

Población en Santiago Sánchez

\begin{tabular}{|l|c|c|c|c|c|c|c|}
\hline Visita Año & Tribut. & Muj. & Niños/as & Reserv. & Huérf. & Ausent. & Total \\
\hline 1653 & 21 & 22 & 26 & 4 & 6 & 7 & 79 \\
1673 & 47 & & & & & & 47 \\
1717 & 9 & 8 & 4 & 1 & - & 1 & 22 \\
1721 & 3 & 5 & 5 & 1 & 2 & 3 & 16 \\
\hline
\end{tabular}

${ }^{42}$ Cuando se inició la investigación intentábamos indagar acerca del rol que cumplían los frailes franciscanos en las reducciones con respecto al trabajo impuesto por los encomenderos o los eventuales mandamientos de los oficiales. Nos preguntábamos si acaso protegían a los indios frente a las solicitudes de ambos grupos. En la visita del oidor Garabito nos encontramos, sin embargo, que en general funcionan como testigos en favor de los encomenderos sobre lo que pesaban las quejas de los indígenas. ABNB. 1653.29

${ }^{43}$ Esta campaña finalmente no se realizó porque se desvaneció el peligro, pero es un ejemplo interesante de las solicitudes de indios realizadas por el estado. ANH. Actas Corrientes. Tomo IV. Pág. 372

${ }^{44}$ Ibídem. Tomo IV. Pág.557

${ }^{45}$ El padrón de 1679 refleja solo el número de tributarios y reservados sin sus familias. 


\section{Cuadro 4}

Población en Santa Lucía

\begin{tabular}{|l|c|c|c|c|c|c|c|}
\hline Visita Ano & Tribut. & Muj. & Niños/as & Reserv. & Huérf. & Ausent. & Total \\
\hline 1653 & 33 & 48 & 34 & 9 & 8 & 24 & 132 \\
1673 & 35 & & & & & & 35 \\
1718 & 8 & 12 & 10 & 6 & 2 & & 38 \\
\hline
\end{tabular}

Más allá de que el interés estaba puesto en los tributarios, se pueden determinar número de huidos, ausentes y la composición de la familia indígena. Todos informes que no se pueden obtener con otras fuentes en siglo XVII en la región.

En los tres cuadros se presenta la población encomendada según las visitas de los siglos XVII y principios del XVIII. Itatí es la reducción que presenta una mayor secuencia en cuanto a sus controles. Se han encontrado visitas periódicas, sobre todo durante el siglo XVIII, mientras que de las otras dos reducciones los datos son menores y en general no nos permiten realizar un estudio de la población, porque no se registraron el total de habitantes ni de encomiendas.

En general la población de Itatí, mantiene cierta estabilidad durante ambos siglos en su población, hay algunos registros que no permiten comparaciones porque sólo se consignó a los tributarios.

En el siglo XVIII las visitas presentan otras características. No son tan detalladas, si bien son más frecuentes, por ejemplo para el caso de Itatí. Los únicos datos detallados y que nos merecen confianza, son los referidos a tributarios, reservados y niños varones, que son los que interesan a la corona por cuestiones fiscales. Los datos referidos a mujeres y niñas son muy relativos. En algunas visitas aparecen en detalle, en otros, no se las tuvieron en cuenta por lo que los totales de población serán siempre aproximados.

De todos modos analizar la evolución diacrónica de las visitas nos permite verificar algunos cambios que se fueron sucediendo en lo referido a los indios y a la reducción. Por

Figura 3

\section{Estructuras Familiares en Itatí. 1717}

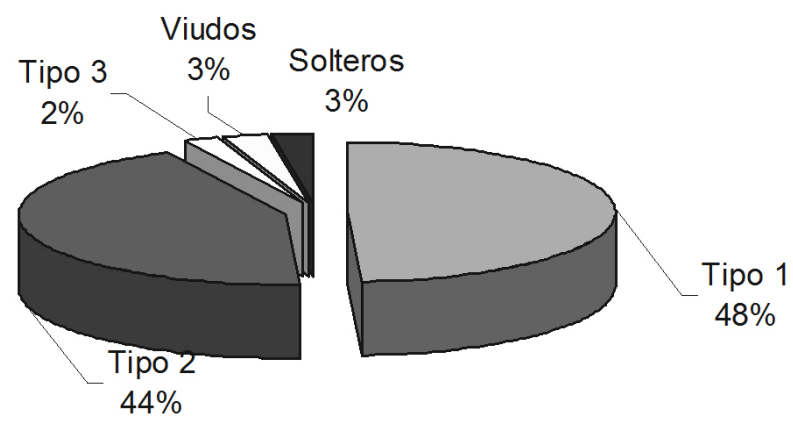


ejemplo el número de encomiendas, se puede comprobar si se hicieron nuevas concesiones, depósitos, etc.

Por ejemplo en el padrón de 1717 no se registraron a las niñas, sólo a las mujeres casadas. Por eso todos los análisis que se pueden hacer sobre esta visita son estimativos en cuanto a sus resultados porque nos faltan los datos que mencionamos. Si bien es una constante el hecho de no tener en cuenta el número de niñas, en este caso ni siquiera se las consigna. Hay un descenso importante en el número de tributarios $(68 \%)$ con respecto al último padrón analizado del siglo XVII. En este siglo se hacen más frecuentes los mandamientos solicitados por funcionarios para eventuales tareas, que implicaban en ocasiones viajes a otros territorios. Si bien el número de ausentes no es importante, podemos suponer también en este caso un subregistro en esta categoría.

El número de reservados aumenta considerablemente con respecto al siglo XVII, aunque es necesario aclarar que en este padrón por primera vez aparecen registrados todos los caciques y sus descendientes hasta cacique séptimo y octavo.

Intentamos acercarnos a un análisis de las estructuras familiares con los datos que ofrece el documento de 1717. Se tuvieron en cuenta tres tipos de familias:

Tipo 1: Matrimonio con hijos varones

Tipo 2: Matrimonio sin hijos varones

Tipo 3: Viudos varones con hijos varones

También se tuvieron en cuenta en el mismo gráfico al grupo de los solitarios: varones solteros y a los viudos.

Los matrimonios con hijos aparecen en mayor porcentaje, sigue en importancia el grupo de matrimonios sin hijos. Es una constante esta característica, ya en el siglo XVII se habían encontrado en el pueblo un alto porcentaje de familias sin hijos. Aunque estos datos se debe tomar con cuidado (recordemos que no fueron registradas las niñas) si bien en el documento se menciona la frase "sin hijos" sin ofrecer más detalles, es muy probable que se refiera a "sin hijos" varones.

Los viudos con hijos presentan un porcentaje muy bajo, al igual que los solteros y viudos sin hijos. El casamiento es indudablemente el paso obligado para todos los habitantes, de allí el bajo porcentaje de solteros.

En 1719 Francisco de Noguera Salguero realizó otra visita a Itatí, específicamente para registrar a los indios y analizar los daños que causó una gran peste que azotó a la región. Los datos que arroja esta visita son muy particulares. Hay un descenso muy importante de la población que puede explicarse por mortalidad y movimientos migratorios causados por la peste.

La visita de 1721 refleja claramente la nueva política implementada con respecto a las concesiones de encomiendas y de alguna manera la pérdida paulatina de importancia de la institución. Sólo se registran cuatro encomiendas, cuyos titulares eran descendientes de beneméritos de la conquista y cumplían con las confirmaciones correspondientes y nueve depósitos, cuatro de ellos nuevos otorgados en un breve lapso de dos años. 
Lo notorio en este registro es que la población logra una recuperación con respecto a 1719, es probable que (siguiendo la hipótesis planteada anteriormente) hayan regresado algunos migrantes por la peste, ya que dos años representa un período muy corto de tiempo para lograr un crecimiento de la población sólo con nuevos nacimientos.

Se da un pequeño aumento del número de tributarios, aunque todavía no alcanza los niveles de 1717. Aumentan también las mujeres y los niños. Este padrón de 1721 registra ya a las niñas pertenecientes a cada una de las familias, de todos modos los números totales de las mismas nos hacen suponer también niveles de subregistros importantes en esta categoría.

\section{Figura 4}

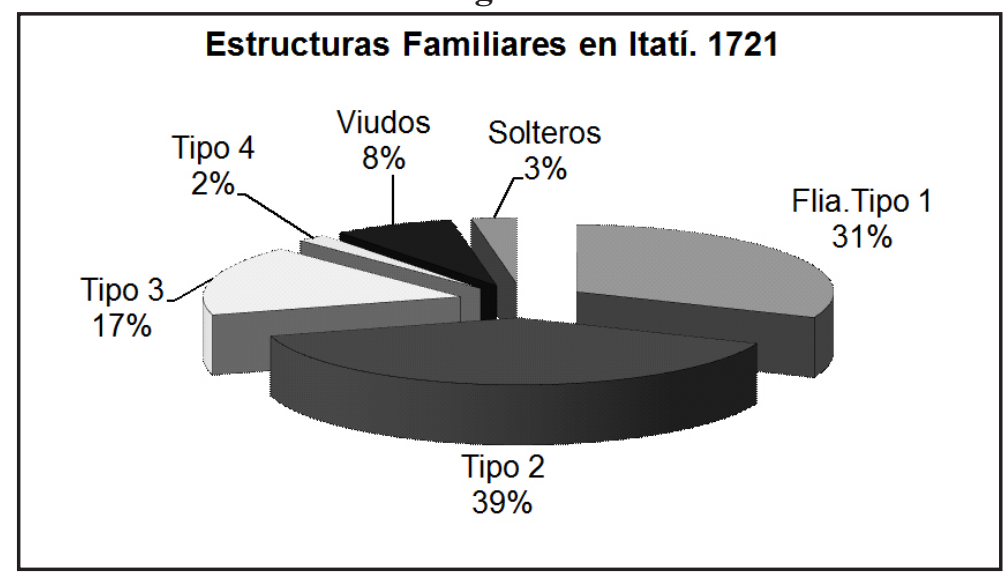

Las estructuras familiares en 1721, presentan algunos cambios con respecto a los tipos de familia encontrados hasta 1719. Se agregó un nuevo grupo que denominamos Tipo 4, madres solteras con hijos. Este es el primer padrón en donde se hace mención a esta situación, si bien solo alcanzan el $2 \%$ es importante tenerlas en cuenta. Un aspecto interesante a destacar sobre este grupo de mujeres es que aparecen consignadas en ocasiones como "rameras" con hijos lo que nos refleja de alguna manera, cuál era la visión del amanuense sobre estas mujeres. No podemos saber si dentro de la reducción eran consideradas por sus pares de la misma manera o es sólo la posición del funcionario encargado del registro.

El mayor porcentaje (al igual que en 1719) está constituido por los matrimonios sin hijos, en este caso como se registraron las niñas, los consideramos sin hijos literalmente ya que en los otros registros se hacía referencia a "sin hijos" varones. Siguen en importancia las familias nucleares con hijos. El tipo 3 (viudos con hijos) aumentó considerablemente, situación que se esperaba a partir de la mencionada peste. Si bien descendió el porcentaje de los viudos sin hijos, sigue siendo considerable con respecto a registros anteriores.

\section{Algunas consideraciones sobre la importancia de las visitas}

Quisimos a través de algunos de los planteos descriptos anteriormente ofrecer algunos interrogantes y problemas que se fueron presentando en el proceso de nuestras 
investigaciones al utilizar las visitas como fuentes. Quedan otras cuestiones pendientes que no incluimos por el recorte que hicimos.

Algunos autores consideran que estas fuentes son las más concluyentes para un estudio básico de la población ${ }^{46}$, ya que las fuentes fiscales presentan múltiples problemas a la hora de elaborar y desglosar los tributos ingresados en las cajas para luego valorar el número de tributarios. Los archivos parroquiales, muy ricos, sin duda, presentan innumerables lagunas por deterioro o pérdida de documentación. En el caso concreto de Corrientes los documentos de los archivos parroquiales datan recién de 1760 aproximadamente, por lo que sobre siglo XVI y XVII y primera mitad del XVIII no se puede acudir a ellos.

Otra posible fuente para utilizar son las concesiones de encomiendas, en ellas se debía anotar el número de tributarios, pero no siempre se cumplía con este detalle en dichos registros. Por consiguiente quedan las visitas como fuentes de posible consulta para reconstruir los primeros siglos de los pueblos de indios correntinos.

Hoy en día, historiográficamente existe un replanteo con respecto a la credibilidad de los números de éstas fuentes, algunos autores insisten en la "representación" de un mundo a partir de estos datos, muy lejano a la realidad y advierten acerca de la necesidad de tomar los datos con mucha sutileza ${ }^{47}$.

Coincidimos plenamente con ésta postura y precisamente esta es la lectura que pretendemos hacer de las visitas en este territorio.

Otro aspecto interesante en las visitas son los detalles descriptivos de los encomendados en algunas de ellas, sobre todo en lo que se refiere a: nombres, edades, estado civil, relaciones de parentesco, vestimentas, descripciones de tipo físicas (se hacen alusiones a defectos físicos o de nacimiento que impiden trabajar, por ejemplo "nubes en los ojos" "corto de una pierna") ${ }^{48}$. Hay claros detalles también con respecto a las mujeres, más allá de que no tributaban

Más allá de todas las preguntas que surgen al trabajar con ellas, debemos destacar las posibilidades que ofrecen de abordar el estudio de una sociedad, desde diversos enfoques. Quizás uno de los aspectos más ricos de la documentación de visitas, tiene que ver con la Historia Social. A partir del análisis de las mismas se pueden conocer también aspectos de la administración política y local de los pueblos de indios, el tributo y la dominación, las relaciones entre encomenderos y encomendados, la vida cotidiana, la religiosidad.

Es posible comprobar a través de estas fuentes, algunas disposiciones legales establecidas para los pueblos de indios como por ejemplo, el hecho de que no podían habitarlos otros grupos que no fueran indígenas. En el caso de las reducciones correntinas, se cumplió efectivamente con esta disposición y recién en las últimas visitas del siglo XVIII se puede detectar la presencia de algunos mestizos.

En lo que se refiere al resguardo de tierras de los indios que habitaban en los pueblos,

\footnotetext{
${ }^{46}$ Julián Ruiz Rivera. "Las visitas a la tierra en el siglo XVII"... ob. cit. p.17

${ }^{47}$ Jorge A.Guevara Gil y Frank L. Salomón. ob. cit.

${ }^{48}$ Visita del oidor Andrés Garabito de León. ABNB. EC. 1653.7
} 
también es posible verificar si se conservaron las tierras en régimen de comunidad y de usufructo individual de cada poblador. En las visitas se hacen frecuentes menciones a las "parcelas" de tierras que corresponden a las familias.

Las fuentes nos permiten conocer como funcionaban internamente las encomiendas, cómo se aplicaba el tributo, el tipo de trabajo que realizaban los indios en el territorio correntino, la vigencia del servicio personal en algunos casos, más allá de la legislación que desde las Ordenanzas de Alfaro había sido muy clara en este aspecto.

La vida cotidiana también aparece en estos documentos, la referencia a los domingos y fiestas de guardar, el descanso como necesario y merecido. De allí las numerosas quejas a los visitadores cuando los encomenderos no lo respetaban.

Las mujeres sin lugar a dudas cumplían un rol muy importante dentro de la sociedad, más allá de su proporción numérica, que es significativa en todos los registros, asumían el control de la familia ante la ausencia de los maridos, ausentes en cumplimiento de la mita o bien fugitivos. La mujer quedaba a cargo, entonces, de reconstruir la familia indígena desestructurada.

La religiosidad juega un papel fundamental en la vida del pueblo, en el caso de Itatí, la devoción a la Virgen y las fiestas en su honor están presentes en las fuentes. La vida estaba marcada indudablemente por el ritmo del trabajo y el ocio de los días festivos, al igual que en la Europa de aquel tiempo para cualquier tipo de campesinado.

Las visitas sin lugar a dudas son fuentes significativas para el estudio de diversos aspectos de la historia colonial, sobre todo de los primeros siglos de la conquista, y con más razón en territorios marginales y alejados de los grandes centros, como es el caso de Corrientes en los siglos XVII y XVIII. El hallazgo y posterior estudio de estas fuentes contribuye de gran manera a reconstruir en parte el funcionamiento y las implicancias de la aplicación de una institución como la encomienda desde épocas tempranas y de la que pocas fuentes se han conservado.

\section{Fuentes}

Siglas utilizadas:

Archivos

ABNB Archivo y Biblioteca Nacionales de Bolivia. (Sucre)

AGI Archivo General de Indias. (Sevilla)

AGN. Archivo General de la Nación. (Buenos Aires)

AGPC Archivo General de la Provincia de Corrientes.

BNRJ Biblioteca Nacional de Río de Janeiro

\section{Colecciones Documentales}

ANH Actas Corrientes. Academia Nacional de la Historia. Actas Capitulares de Corrientes. Buenos Aires.1941-1946.

RLI Recopilación de las Leyes de Indias 


\section{Bibliografía}

Arretx, C., Mellafe, R., Somoza, J. Demografía Histórica en América Latina. Fuentes y métodos. CELADE. Serie E, 1002, San José, Costa Rica. 1983.

Boixadós, Roxana y Carlos Eduardo Zanolli. La visita de Luján de Vargas a las encomiendas de La Rioja y Jujuy (1693-1694). Estudios Prelimiares y fuentes. Buenos Aires, Universidad Nacional de Quilmes, 2003. 320 pp. (15 X 20)

Block, David, "Treinta años de visitas de indios, una bibliografía anotada". En Anuario 2000 del Archivo y Biblioteca Nacionales de Bolivia. Sucre. p. 578

Boleda, Mario y Enrique Tandeter. Las poblaciones andinas. Estudio de la dinámica demográfica de Chayanta en los siglos XVII-XVIII. Buenos Aires, Alianza Editorial, 2004.

Borah, Woodrow. El juzgado general de indios en la Nueva España. México, Fondo de Cultura económica, $1985.488 \mathrm{pp}$

Burga, Manuel; De la encomienda a la hacienda capitalista. El valle de Jequetepeque del siglo XVI al XX. Lima. Instituto de Estudios Peruanos. 1976.

Celton, Dora. La población de la provincia de Córdoba a fines del siglo XVIII. Academia Nacional de la Historia. Buenos Aires. 1993.

Cervera, Miguel. Historia de la ciudad y provincia de Santa Fe.1573-1853. Santa Fe. La Unión, 1907. vol 1. p. 77-90

Céspedes del Castillo, Guillermo. "La visita como institución indiana". En: Anuario de Estudios Americanos, III, 1946, Pág. 984-1025

Doucet, Gastón Gabriel. "Génesis de una visita de la tierra. Los orígenes de la visita de las gobernaciones de Tucumán y Paraguay por el Licenciado Don Francisco de Alfaro". En Revista de Historia del Derecho. Instituto de Investigaciones de Historia del Derecho. 14, Buenos Aires, 1986. Pág. 123-220

"Introducción al estudio de la visita del oidor Don Antonio Martínez Luján de Vargas a las encomiendas de indios del Tucumán”. Boletín del Instituto de Historia Argentina y Americana Doctor Emilio Ravignani. 26. Buenos Aires, 1980. Pág. 205-246.

"Los autos del visitador Don Antonio Martínez Luján de Vargas". Revista de Historia del Derecho. Instituto de Investigaciones de Historia del Derecho. 8, Buenos Aires, 1980. Pág 123-154.

Farberman, Judith. "Indígenas, encomenderos y mercaderes: Los pueblos de indios santiagueños durante la visita de Luján de Vargas (1693"). En Anuario IEHS. Tandil Universidad Nacional del Centro de la Provincia de Buenos Aires. 6. 1991. Pág.43-57

Migrantes y Soldados. Los Pueblos de indios de Santiago del Estero en 1786 y 1813. Cuadernos del Instituto de Historia Argentina y Americana Dr. Emilio Ravignani. (1992).

"Trabajar con fuentes parcas en regiones marginales. Reflexiones metodológicas acerca del estudio de las poblaciones indígenas rurales en el Noroeste Argentino. Siglos XVIII y XIX”. En: Revista Historia de América. Instituto panamericano de Historia y Geografía. México. 127. Julio-Diciembre 2000.Págs. 35-62

Ferreiro, Juan Pablo. “Tierras, encomiendas y Elites. El caso de Jujuy en el siglo XVII”. En: Anuario de Estudios americanos. Separata del Tomo II. NI. Sevilla. 1995 Pag 189-214.

Garavaglia, Juan Carlos. Economía, sociedad y regiones. Buenos Aires. Ediciones de la Flor. 1987 y Gelman, Jorge. La historia rural del Río de la Plata, 1600-1850.

Balance de una renovación historiográfica, m.s. 1994

Mercado Interno y Economía Colonial. México. Grijalbo. 1983

y Moreno, José Luis. Población, Sociedad, familia y migraciones 
en el espacio rioplatense. Siglos XVIII-XIX. Buenos Aires. Cántaro.1989

Gil Montero, Raquel. "Hogar y Familia: Aproximaciones para una definición desde la antropología y la historia". En. III Jornadas Argentinas de Estudios de la Población. H. Senado de la Nación. Buenos Aires. 1998. Pág. 234-251

Grieshaber, Erwin. "Los padrones de contribución indígena como fuente demográfica: posibilidades y limitaciones." En Anuario del Archivo y Biblioteca Nacionales de Bolivia.1994-1995. Sucre.

Guevara Gil, Jorge A. y Frank L. Salomon. "La Visita Personal de Indios: Ritual Político y creación cel indio en Los Andes coloniales”. Lima: PUCP-Instituto Riva-Agüero, 1997

Idoyaga Molina Anatilde. Sexualidad, reproducción y aborto. Nociones prácticas de mujeres indígenas y campesinas de la Argentina. Buenos Aires, 1999.

Labougle, Raúl De "La reducción Franciscana de Candelaria de Ohoma". En: Revista de la Junta de Historia de Corrientes 3. 1968. Pag. 7-14.

"La reducción Franciscana de Itatî". En Investigaciones y Ensayos (I.E) 3. Bs. As. 1968. Pág 281-323.

"La reducción Franciscana de Santa Lucía de los Astos". En IE N5. Bs. As. 1968. pag. 131-152.

"La reducción Franciscana de Santiago Sánchez". En: IE. Enero- Junio 1970. Nº 8. Pág. 123-153

Lorandi, Ana María. "El servicio personal como agente de desestructuración en el Tucumán colonial". Revista andina. Año 6. $\mathrm{N}^{\circ} 1$. Julio de 1988. Pag 135-173

Maeder, Ernesto. "Asimetría demográfica entre las reducciones franciscanas y jesuitas de guaraníes." En: Revista Complutense de Historia de América. Madrid, 1995. 21.

"La fundación de Corrientes: los hombres y las circunstancias.(15881618)". En: Boletín de la Academia Nacional de la Historia. Bs. As. 1988. Volumen LXI.

Metraux, Alfred. Estudios de Etnografía chaquense. Anales del Instituto de etnografía americana. Universidad Nacional de Cuyo. 1944. Tomo V

Miranda, Jospe. El tributo indígena en la Nueva España durante el siglo XVI, México, El Colegio, 1952.

Murra, John M. Visita de la provincial de León de Huánuco en 1562: Iñigo Ortiz de Zúñiga, visitador. Huanuco. Universidad Nacional Hermilio Valdizán. Facultad de Letras y Educación, 19671972. 2v.

Presta, Ana María. Los encomenderos de la Plata.1550-1600. Encomienda, familia y negocios en Charcas Colonial .Lima, Instituto de Estudios Peruanos.2000.

Rostorowsky, María y Pilay Remy. Las visitas de Cajamarca 1571-1572. Documentos, Instituto de Estudios Peruanos, Lima, 1992.

Ruiz Rivera, Julián "Las visitas a la tierra en el siglo XVII como fuente de Historia Social" En: Estudios sobre política indigenista española en América. 3 vol., Valladolid 1975-197

Sánchez Bella, Ismael . Derecho Indiano: Estudios. I: Las Visitas Generales en la América Española, siglos XVI-XVII. Pamplona. Universidad de Navarra, 1991.XI, 357

Tandeter, Enrique. "Teóricamente ausentes, teóricamente solas. Mujeres y hogares en los Andes Coloniales. (Sacaca y Acasio en 1614). En Revista Andes. Antropología e Historia. Nº 8, 1997. pp. 11-25

Tovar Pinzón, Hermes. "El saber indígena y la administración colonial española: la visita a la provincia de Mariquita de 1559" Anuario Colombiano de Historia Social y de la Cultura, 22, 1995, p.10

Zabala, Silvio. La encomienda indiana. Madrid. Centro de Estudios Históricos. 1935

Zanolli, Carlos. Tierra, encomienda e identidad. Omaguaca (1540-1638). Buenos Aires, Sociedad Argentina de Antropología.2005 


\title{
Resumen
}

Las visitas realizadas a la ciudad de Corrientes y a los pueblos de indios que pertenecieron a su jurisdicción durante los siglos XVII y XVIII, constituyen fuentes interesantes y en algunos aspectos "generosas" por la información específica que ofrecen sobre la población indígena encomendada que habitaba en las reducciones y en la ciudad como yanaconas sirviendo en las casas o chacras de los encomenderos. Siendo el objetivo conocer detalles de la población tributaria y sus familias e intervenir ante posibles irregularidades, los informes destacan especialmente el estado cuantitativo y algunos aspectos de la situación de los indígenas de los cuatro pueblos de indios de la región: Itatí, conformada por guaraníes y Santiago Sánchez, Candelaria de Ohoma, Santa Lucía de los Astos constituidas por grupos chaqueños.

Una de las principales preguntas que surgen permanentemente al realizar nuestra investigación, es hasta qué punto estas fuentes contribuyen a la reconstrucción de la realidad demográfica de estas poblaciones. Nos proponemos, entonces en este trabajo reflexionar acerca de las posibilidades y limitaciones que ofrecen los datos aportados por estos documentos oficiales, teniendo en cuenta que son casi los únicos disponibles de ésta época en la región.

$$
<\text { Encomiendas }><\text { Visitas }><\text { Siglo XVII }><\text { Siglo XVIII }><\text { Corrientes }>
$$

\begin{abstract}
The visits to the city of Corrientes and the towns of Indians who belonged to his jurisdiction during the seventeenth and eighteenth centuries, are sources interesting and in some respects "generous" with the specific information they provide of the indigenous towns who lived in mandated and reductions in the city as yanaconas serving in the homes or farms of the encomenderos. Being the objective details of the tax people and their families to address possible irregularities, the reports highlight especially the status and quantitative aspects of the situation of indigenous peoples of the four Indians in the region: Itatí, formed by Guarani and Santiago Sanchez, Candelaria Ohoma, Saint Lucia de los Astos formed by chaqueños groups.

One of the major questions that always arise when conducting our research, is to what extent these sources contribute to the reconstruction of the demographic reality of these stocks. We intend, in this paper reflect on the possibilities and limitations offered by Data from these official documents, taking into account that they are almost the only ones available this time in the region.
\end{abstract}

$<$ Encomienda $><$ Visits $><$ XVII Century $><$ XVIII Century $><$ Corrientes $>$ 